\title{
Association of Mean Serum Vitamin B-12 levels in Patients with Type II Diabetes Mellitus patients with and without Metformin therapy.
}

\author{
DR. ABDUL MANNAN JEHANGIR \\ MBBS, NISHTAR HOSPITAL, MULTAN, PAKISTAN. \\ DR. AAMNA ASGHAR \\ MBBS, NISHTAR HOSPITAL, MULTAN, PAKISTAN.
}

DR. AYESHA IFTIKHAR

MBBS, NISHTAR HOSPITAL, MULTAN, PAKISTAN.

\begin{abstract}
:
Objective: To determine mean serum vitamin B12 levels in patients with type II diabetes mellitus using metformin.
\end{abstract}

Study Design: Prospective Cross sectional Study Location and Duration: Department of Medicine, Nishtar Hospital Multan, from March 2018 to September 2019.

\section{Methodology:}

Ninety two patients were involved after getting informed consent. $\mathrm{HbAl} 1_{c}$, body mass index and blood pressure and deficiency for vitamin B12 was assessed by using electro-chem-iluminescence immunoassay method. B12 levels were categorized as normal $(>220 \mathrm{pg} / \mathrm{ml})$, possibly deficient $(150$ to $220 \mathrm{pg} / \mathrm{ml})$ and definitely deficient $(<150 \mathrm{pg} / \mathrm{ml})$. Neuropathy was assessed and was classified by using Toronto clinical scoring system by the researcher himself. All the data was subjected to statistical analysis using computer software SPSS version 23. Continuous variables were analyzed by their mean and standard deviation while quantitative variables were analyzed by frequency and percentages. Chi square test was applied and $\mathrm{P}$ value less than or equal to 0.05 was taken as significant.

Results: Mean Serum B-12 levels were $378.42 \pm 161.27 \mathrm{pg} / \mathrm{ml}$ and $488.90 \pm 147.02 \mathrm{pg} / \mathrm{ml}$ in metformin and nonmetformin groups, respectively. The difference was statistically significant $(\mathrm{p}=0.001)$. The patients who were possibly deficient and definitely deficient were $15(28.30 \%)$ and $5(9.43 \%)$ in metformin group and were significantly more $(\mathrm{p}=0.006)$ than non-metformin group i.e. $4(10.26 \%)$ and 0 . The mean Toronto Neuropathy Score was statistically different $(\mathrm{p}<0.001)$ between metformin group $(6.03 \pm 1.73)$ and non-metformin group $(4.13 \pm 1.75)$. The patients who had mild neuropathy and moderate neuropathy were $23(43.39 \%)$ and $5(9.43 \%)$ in metformin group, while $6(15.38 \%)$ and $2(5.13 \%)$ in non-metformin group. Statistically, both the groups were significantly different $(\mathrm{p}=0.005)$.

Conclusion: At the end of this study conclusion can be made that metformin use for type II diabetes mellitus is strongly associated with vitamin B12 deficiency and worsening of already susceptible neuropathy.

Keywords: vitamin B12, Type II diabetes mellitus, neuropathy. 
DOI: $10.7176 / \mathrm{JMPB} / 62-15$

Publication date: December $31^{\text {st }} 2019$

\section{Introduction:}

For almost forty years it has been known that metformin use has a hand in lowering vitamin B12 levels. Vitamin B12 deficiency is a common phenomenon among the elderly ${ }^{1}$. Clinically it may present as hematological disease or neuropsychiatric illness and at times it is difficult to detect in certain scenarios ${ }^{2}$. Usually vitamin B12 deficiency is basically caused by malabsorption leading to classical condition of pernicious anemia. Two case reports have been found which showed evidence of vitamin B12 deficiency causing peripheral neuropathy ${ }^{3}$ and in the light of these reports annual supplementation of vitamin B12 has been recommended for the patient receiving metformin for type II diabetes mellitus. In some parts of the world it is now considered as an empirical therapy for peripheral neuropathy.

Metformin is one of the first line drugs in the treatment of patients with type II diabetes mellitus ${ }^{4}$ and is associated least no. of side effects. It is strictly anti-hyperglycemic and also reduces the overall morbidity and mortality in diabetic patients. But it has one major setback which is deficiency of vitamin B12, a preventable and very much recoverable condition if diagnosed at optimum time. This deficiency can lead in deterioration of already present peripheral neuropathy in diabetic patients. In order to differentiate vitamin B12 deficiency caused peripheral neuropathy and usual peripheral neuropathy caused by the diabetes itself a systemized and well performed study is required. So that a perfect estimate of the level of deficiency can be developed which leads to the development of B12-deficiency induced neuropathy. Vitamin B12 concentrations in blood are not very good predictors of B12 deficiency ${ }^{5}$, as it is usually normal even in clinically diagnosed B12 deficiency patients. On the other hand mild decrease in concentration of B12 in serum does not establish its deficiency. For this purpose two specific tests have been developed which are more sensitive to B12 deficiency as compared to B12 concentration itself. Holotrancobalamin (holoTC) ${ }^{6}$ is a biological fraction of vitamin B12 and methylmelonic acid (MMA), are two markers for the diagnosis of status of vitamin B12 7 .

Correlation between vitamin B12 deficiency and metformin use has been studied worldwide but there are very little evidence present about the level to which it is decreased and its clinical impact as changes in neurological status and peripheral neuropathy. Moreover this correlation has not been studies in our population that is why we are not only going to assess the correlation between long term metformin use but also going to assess whether this deficiency has any impact over neuropathy among patients being treated with metformin for type II diabetes mellitus.

\section{Materials and Methods:}

An observational, cross-sectional study was conducted in Department of Medicine, Nishtar Hospital Multan from March 2018 to September 2019. Study was conducted on consecutive patients with type 2 diabetes mellitus on drug treatment seen at outpatient department of Nishtar Hospital Multan. Ethical approval for this study was obtained from Hospital Ethics Committee. Ninety two patients were involved after getting informed consent. Sampling technique of Non probability consecutive sampling was used to collect the sample size. Sample was calculated using the reference study by AK Singh et al ${ }^{8}$. Patients were excluded if they gave history of alcoholism, ongoing pregnancy, liver disease, renal disease, thyroid disorders or history suggestive of malabsorption disorders. Type 1 diabetes mellitus patients were also excluded from analysis. Patients were selected by adhering strictly to these inclusion and exclusion criteria.

Most of the patients taking part in this study were on hypoglycemic drugs for their diabetes mellitus type II. Detailed drug history was obtained and diet history was recorded as well. Patients were divided into two groups; those on treatment with metformin were segregated as one group and others as the second group. Cumulative dosage of metformin and duration of the use of the drug was recorded.

After detailed history and examination following parameters were measured and recorded in the form of a performed performa; $\mathrm{HbA} 1_{\mathrm{c}}$, body mass index and blood pressure. Deficiency for vitamin B12 was assessed by using electro-chem-iluminescence immunoassay method. Samples for serum levels were kept for no more than 8 hours and at a temperature range of 15 to $30^{\circ} \mathrm{C}$. B12 levels were categorized as normal ( $\left.>220 \mathrm{pg} / \mathrm{ml}\right)$, possibly deficient (150 to $220 \mathrm{pg} / \mathrm{ml})$ and definitely deficient $(<150 \mathrm{pg} / \mathrm{ml})$. 
Standard neurological examination was performed on all the patients who took part in study including, deep tendon reflexes, tone and power of the muscles and sensory function. At the end of all the procedures of history, general physical examination and standard neurological examination, the resultant outcome of neuropathy was assessed and was classified by using Toronto clinical scoring system by the researcher himself. Gradation of the patients was carried out on the basis of score and grades were described as 0 to $5=$ No neuropathy, 6 to 9 mild neuropathy, 10 to 12 moderate neuropathy and greater than 12 as severe neuropathy. All the data was subjected to statistical analysis using computer software SPSS version 23. Continuous variables were analyzed by their mean and standard deviation while quantitative variables were analyzed by frequency and percentages. Chi square test was applied and $\mathrm{P}$ value less than or equal to 0.05 was taken as significant.

\section{Results:}

Mean age, weight, $\mathrm{HbA} 1_{c}$, Mean blood pressure, hemoglobin and Mean Corpuscular Volume were $42.87 \pm 10.07$ years, $58.32 \pm 13.84 \mathrm{~kg}, 7.90 \pm 0.60,124.96 \pm 7.30 \mathrm{mmHg}, 12.07 \pm 2.91 \mathrm{mg} / \mathrm{dl}$ and $91.85 \pm 11.31 \mathrm{fl}$ in metformin group; and $46.82 \pm 9.18$ years, $62.31 \pm 14.31 \mathrm{~kg}, 8.04 \pm .65,126.10 \pm 6.22 \mathrm{mmHg}, 12.15 \pm 2.89 \mathrm{mg} / \mathrm{dl}$ and $92.15 \pm 11.23 \mathrm{fl}$ in Non-metformin group. Both the groups were comparable. The patients who were simultaneously using insulin were $13(24.5 \%)$ in metformin group and $19(48.7 \%)$ in non-metformin group. The difference was statistically significant $(\mathrm{p}=0.016)$. (Table-I)

Mean Serum B-12 levels were $378.42 \pm 161.27 \mathrm{pg} / \mathrm{ml}$ and $488.90 \pm 147.02 \mathrm{pg} / \mathrm{ml}$ in metformin and non-metformin groups, respectively. The difference was statistically significant $(\mathrm{p}=0.001)$. The patients who were possibly deficient and definitely deficient were $15(28.30 \%)$ and $5(9.43 \%)$ in metformin group and were significantly more $(\mathrm{p}=0.006)$ than non-metformin group i.e. $4(10.26 \%)$ and 0 . (Table-II)

The mean Toronto Neuropathy Score was statistically different $(\mathrm{p}<0.001)$ between metformin group $(6.03 \pm 1.73)$ and non-metformin group $(4.13 \pm 1.75)$. The patients who had mild neuropathy and moderate neuropathy were 23 $(43.39 \%)$ and $5(9.43 \%)$ in metformin group, while $6(15.38 \%)$ and $2(5.13 \%)$ in non-metformin group. Statistically, both the groups were significantly different $(\mathrm{p}=0.005)$. (Table-II)

\section{Table-I}

\section{Baseline Variables}

\begin{tabular}{|l|c|c|c|}
\hline \multicolumn{1}{|c|}{ Variable } & $\begin{array}{c}\text { Metformin } \\
\mathbf{N = 5 3}\end{array}$ & $\begin{array}{c}\text { Non-metformin } \\
\mathbf{N = 3 9}\end{array}$ & p-value \\
\hline Age (Years) & $42.87 \pm 10.07$ & $46.82 \pm 9.18$ & .057 \\
\hline Male n (\%) & $44(83)$ & $33(84.6)$ & .838 \\
\hline Weight (Kg) & $58.32 \pm 13.84$ & $62.31 \pm 14.31$ & .182 \\
\hline HbA1 & $7.90 \pm 0.60$ & $8.04 \pm .65$ & .280 \\
\hline Mean blood pressure (mmHg) & $124.96 \pm 7.30$ & $126.10 \pm 6.22$ & .433 \\
\hline Hemoglobin (mg/dl) & $12.07 \pm 2.91$ & $12.15 \pm 2.89$ & .898 \\
\hline Mean Corpuscular Volume (fl) & $91.85 \pm 11.31$ & $92.15 \pm 11.23$ & .898 \\
\hline
\end{tabular}

Parallel Therapy

\begin{tabular}{|l|c|c|c|}
\hline Insulin n (\%) & $13(24.5)$ & $19(48.7)$ & .016 \\
\hline Sulfonylureas n (\%) & $39(73.6)$ & $33(84.6)$ & .205 \\
\hline Pioglitazone n (\%) & $21(39.6)$ & $14(35.9)$ & .716 \\
\hline
\end{tabular}

Variables are mentioned as mean \pm S.D or number (percentage); Independent $t$ test and chi-square test was applied. 
Table-II

Vitamin B-12 level and Toronto Clinical Neuropathy Score

\begin{tabular}{|c|c|c|c|}
\hline Variable & Metformin & Non-Metformin & p-value \\
\hline Serum B-12 (pg/ml) & $378.42 \pm 161.27$ & $488.90 \pm 147.02$ & 0.001 \\
\hline Possible deficiency N (\%) & $15(28.30)$ & $4(10.26)$ & 0.006 \\
\hline Definite Deficiency N (\%) & $5(9.43)$ & $0(0)$ & $<0.001$ \\
\hline Toronto Neuropathy Score & $6.03 \pm 1.73$ & $4.13 \pm 1.75$ & \multirow{2}{*}{0.005} \\
\hline No Neuropathy N (\%) & $25(47.17)$ & $31(79.49)$ & \\
\hline Mild Neuropathy N (\%) & $23(43.39)$ & $6(15.38)$ & \\
\hline Moderate Neuropathy N (\%) & $5(9.43)$ & $2(5.13)$ & \\
\hline
\end{tabular}

Variables are mentioned as mean \pm S.D or number (percentage); Independent $t$ test and Fischer exact test was applied.

\section{Discussion:}

In this study results are in favor of the notion that metformin use in the treatment of type II diabetes mellitus does result in lowering the serum vitamin B12 levels. Peripheral neuropathy was also evidently more in the metformin users and was associated with lower levels of vitamin B12 in serum.

Previously numerous studies have gave the evidence of lowering of vitamin B12 in people who use metformin for longer of duration of time ${ }^{9,10,11,12,13}$ and a few case reports ${ }^{14,15}$ have also gave the evidence of association of increased incidence of neuropathy with low levels of B12 in serum and metformin use chronically. In a study $18 \%$ of patients in metformin group had the evidence of low B12 levels as compared to the placebo group ${ }^{10}$. Another retrospective study gave almost similar results in which $13 \%$ patients with chronic use of metformin had the evidence of deficiency of vitamin B12 and 5.6\% of the patients were definitely deficient in their serum levels of vitamin B12 $(<150 \mathrm{pg} / \mathrm{ml})^{9}$. A cross sectional study in the region of Canada ${ }^{12}$ and Hong Kong ${ }^{11}$ showed similar results to our study as they also observed deficiency of vitamin B12 in metformin user diabetic of type two diabetes mellitus as $31 \%$ and $37 \%$ respectively.

Mechanism by which B12 deficiency occurs has been shown to involve calcium dependent ileal membrane antagonism, which results in low levels of serum B12 and malabsorption of B12 from lumen by chronic use of metformin. This effect can be reversed by the use of calcium as has been reported in recent studies ${ }^{16}$. A Chinese case control study reported that not only long term use of metformin can cause vitamin B12 deficiency but its higher doses can have the similar effects irrespective of the presence of other clinical variables ${ }^{17}$. A diabetes prevention program outcome study has given similar results to our study stating that metformin use not only lowers serum B12 level but also can cause its complications, like anemia (pernicious anemia) ${ }^{18}$. A meta-analysis performed recently has demonstrated a close relation between chronic metformin use and low levels of vitamin B12 in serum of patients with type two diabetes mellitus ${ }^{19}$. All of these studies have suggested that early detection of serum B12 deficiency is required in long term users of metformin as vitamin B12 deficiency can lead to serious complications like anemia and also can precipitate neuropathic effect of diabetes mellitus.

\section{Conclusion:}

At the end of this study conclusion can be made that metformin use for type II diabetes mellitus is strongly associated with vitamin B12 deficiency and worsening of already susceptible neuropathy. Suggestions can be made that vitamin B12 levels should be assessed in patients with long term metformin use so that hazardous increase of risk among these patients can be prevented.

\section{Conflict of Interest:}

There was no conflict of interest regarding this study.

\section{Funding Source:}

No extra funding was used in this study. 


\section{References:}

1- Kennedy DO. B vitamins and the brain: Mechanisms, dose and efficacy_A review. Nutrients. 2016 Jan 27;8(2):68.

2- Stabler SP. Vitamin B12 deficiency. New England Journal of Medicine. 2013 Jan 10;368(2):149-60.

3- Roy RP, Ghosh K, Ghosh M, Acharyya A, Bhattacharya A, Pal M, Chakraborty S, Sengupta N. Study of Vitamin B12 deficiency and peripheral neuropathy in metformin-treated early Type 2 diabetes mellitus. Indian journal of endocrinology and metabolism. 2016 Sep;20(5):631.

4- Sanchez-Rangel E, Inzucchi SE. Metformin: clinical use in type 2 diabetes. Diabetologia. 2017 Sep 1;60(9):1586-93.

5- Jeruszka-Bielak M, Isman C, Schroder TH, Li W, Green TJ, Lamers Y. South Asian ethnicity is related to the highest risk of vitamin B12 deficiency in pregnant Canadian women. Nutrients. 2017 Mar 23;9(4):317.

6- Sobczyńska-Malefora A, Gorska R, Pelisser M, Ruwona P, Witchlow B, Harrington DJ. An audit of holotranscobalamin ("Active" B12) and methylmalonic acid assays for the assessment of vitamin B12 status: application in a mixed patient population. Clinical biochemistry. 2014 Jan 1;47(1-2):82-6.

7- Oberley MJ, Yang DT. Laboratory testing for cobalamin deficiency in megaloblastic anemia. American journal of hematology. 2013 Jun 1;88(6):522-6.

8- Singh AK, Kumar A, Karmakar D, Jha RK. Associations of B12 deficiency and clinical neuropathy with metformin use in type 2 diabetes patients. Journal of postgraduate medicine. 2013 Oct 1;59(4):253.

9- Reinstatler L, Qi YP, Williamson RS, Garn JV, Oakley GP. Association of biochemical B12 deficiency with metformin therapy and vitamin B12 supplements: the National Health and Nutrition Examination Survey, 1999-2006. Diabetes care. 2012 Feb 1;35(2):327-33.

10- De Jager J, Kooy A, Lehert P, Wulffelé MG, Van der Kolk J, Bets D, Verburg J, Donker AJ, Stehouwer CD. Long term treatment with metformin in patients with type 2 diabetes and risk of vitamin B-12 deficiency: randomised placebo controlled trial. Bmj. 2010 May 20;340:c2181.

11- Liu KW, Dai DL, Ho W Lau E, Woo J. Metformin-associated vitamin B12 deficiency in the elderly. Asian J Gerontol Geriatr 2011;6:82-7.

12- Wile DJ, Cory Toth. Association of metformin, elevated homocysteine, and methylmalonic acid levels and clinically worsened diabetic peripheral neuropathy. Diabetes Care 2010;33:156-61.

13- Dunstan DF, Rees JA, Chen S, Lansdown JA, Moat SJ, Ellis R, et al. An observational study of the effect of metformin on B12 status and peripheral neuropathy. Br J Diabetes Vascular Dis 2012;12:18993.

14- Bell DS. Metformin-induced vitamin B12 deficiency presenting as a peripheral neuropathy. South Med J 2010;103:265-7.

15- Kumthekar AA, Gidwani HV, Kumthekar AB. Metformin associated B12 deficiency. J Assoc Physicians India 2012;60:58-60.

16- Bauman WA, Shaw S, Jayatilleke E, Spungen AM, Herbert V. Increased intake of calcium reverses vitamin B12 malabsorption induced by metformin. Diabetes care. 2000 Sep 1;23(9):1227-31.

17- Ting RZ, Szeto CC, Chan MH, Ma KK, Chow KM. Risk factors of vitamin B12 deficiency in patients receiving metformin. Archives of internal medicine. 2006 Oct 9;166(18):1975-9.

18- Aroda VR, Edelstein SL, Goldberg RB, Knowler WC, Marcovina SM, Orchard TJ, Bray GA, Schade DS, Temprosa MG, White NH, Crandall JP. Long-term metformin use and vitamin B12 deficiency in the Diabetes Prevention Program Outcomes Study. The Journal of Clinical Endocrinology \& Metabolism. 2016 Apr 1;101(4):1754-61.

19- Chapman LE, Darling AL, Brown JE. Association between metformin and vitamin B12 deficiency in patients with type 2 diabetes: A systematic review and meta-analysis. Diabetes \& metabolism. 2016 Nov 1;42(5):316-27. 